\title{
Determinants of Poor Self-rated Health in Korean Adults With Diabetes
}

\author{
Hwi-Won Lee ${ }^{1,2}$, Minkyo Song ${ }^{1,2}$, Jae Jeong Yang ${ }^{1,3}$, Daehee Kang ${ }^{1,2,4}$ \\ ${ }^{1}$ Department of Preventive Medicine, Seoul National University College of Medicine, Seoul; ${ }^{2}$ Department of Biomedical Sciences, Seoul National \\ University Graduate School, Seoul; ${ }^{3}$ Institute of Environmental Medicine, Seoul National University Medical Research Center, Seoul; ${ }^{4}$ Cancer Research \\ Institute, Seoul National University, Seoul, Korea
}

Objectives: Self-rated health is a measure of perceived health widely used in epidemiological studies. Our study investigated the determinants of poor self-rated health in middle-aged Korean adults with diabetes.

Methods: A cross-sectional study was conducted based on the Health Examinees Study. A total of 9759 adults aged 40 to 69 years who reported having physician-diagnosed diabetes were analyzed with regard to a range of health determinants, including sociodemographic, lifestyle, psychosocial, and physical variables, in association with self-rated health status using multivariate logistic regression models. A $p$-value $<0.05$ was considered to indicate statistical significance.

Results: We found that negative psychosocial conditions, including frequent stress events and severe distress according to the psy-

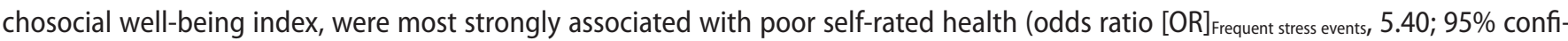
dence interval [Cl], 4.63 to 6.29 ; ORsevere distress, $11.08 ; 95 \% \mathrm{Cl}, 8.77$ to 14.00$)$. Moreover, younger age and being underweight or obese were shown to be associated with poor self-rated health. Physical factors relating to participants' medical history of diabetes, such as a younger age at diagnosis, a longer duration of diabetes, insulin therapy, hemoglobin $A_{1 c}$ levels of $6.5 \%$ or more, and comorbidities, were other correlates of poor reported health.

Conclusions: Our findings suggest that, in addition to medical variables, unfavorable socioeconomic factors, and adverse lifestyle behaviors, younger age, being underweight or obese, and psychosocial stress could be distinc factors in predicting negative perceived health status in Korean adults with diabetes.

Key words: Epidemiology, Self-rated health, Diabetes mellitus, Cohort studies, Health Examinees, Korea

Received: July 31, 2015 Accepted: October 21, 2015

Corresponding author: Daehee Kang, MD, PhD

103 Daehak-ro, Jongno-gu, Seoul 03080, Korea

Tel: +82-2-740-8407, Fax: +82-2-747-4830

E-mail: dhkang@snu.ac.kr

This is an Open Access article distributed under the terms of the Creative Commons Attribution Non-Commercial License (http://creativecommons.org/licenses/by$\mathrm{nc} / 3.0 /$ ) which permits unrestricted non-commercial use, distribution, and reproduction in any medium, provided the original work is properly cited.

\section{INTRODUCTION}

Perceptions of health are currently considered to encompass both physical and psychological dimensions. Self-rated health (SRH) is a self-reported health measure that is valid and widely used in epidemiological studies to assess an individual's integrated perception of health, which may be inaccessible to an external observer [1-3]. Despite the subjective nature of this concept, it can aid in the global assessment of health in terms of biological, psychological, and social dimensions, which may be more sensitive than external measures of health 
for monitoring overall health [1]. In fact, SRH has been shown to predict a range of health outcomes, spanning from morbidity and mortality to future health care use [4,5].

According to a report by the Organization for Economic Cooperation and Development (OECD), Korea ranked 33rd out of 34 OECD member states in perceived health status of the population [6]. Less than half of the total population (36.8\%) reported being in good health, far below the OECD average of $69.0 \%$. A wide range of factors may have influenced those results, and it is imperative that greater emphasis be placed on public health and disease prevention in order to improve population health. Such efforts can begin with specific populations at the local level.

Diabetes has emerged as a new epidemic, with approximately 382 million people living with diabetes globally [7]. In recent years, the proportion of type 2 diabetes has increased, especially in Asia, making this region the epicenter of the diabetes epidemic [7]. Korea is not free from this global phenomenon, with $12.4 \%$ of adults 30 years and older diagnosed with diabetes. This trend continues, with a twofold growth of the diabetic population expected over the next 40 years [8].

So far, only a handful of studies has investigated the association between perceived health status and chronic diseases, such as diabetes, within the Korean population. Some studies have found independent associations between diseases such as hypertension and non-fatal musculoskeletal disorders and poor SRH $[9,10]$. Most studies regarding SRH, however, have been conducted in the general Korean population, rendering it unfeasible to identify factors representative of people with chronic conditions [11,12]. It is necessary to determine the factors associated with negative perceived health among specific subgroups. This study thus aimed to identify the factors associated with poor SRH in diabetic middle-aged Korean adults.

\section{METHODS}

This study was based on a large-scale genomic cohort study, the Health Examinees (HEXA) Study. Described elsewhere in detail, the HEXA Study was launched to investigate the risk factors for major chronic diseases, ranging from epidemiological characteristics and genomic features to gene-environment interactions [13].

\section{Study Population}

A total of 162142 subjects aged 40 to 69 years participated in the HEXA Study between 2004 and 2012. In addition to respondents who answered 'yes' to a question about physiciandiagnosed diabetes in the self-reported survey, only those who were 30 years or older at the time of diabetes diagnosis were included in order to limit the possibility of including cases of type 1 diabetes $(n=10112)[3,14]$. Subjects were also excluded due to missing information about SRH $(n=84)$ or a his-

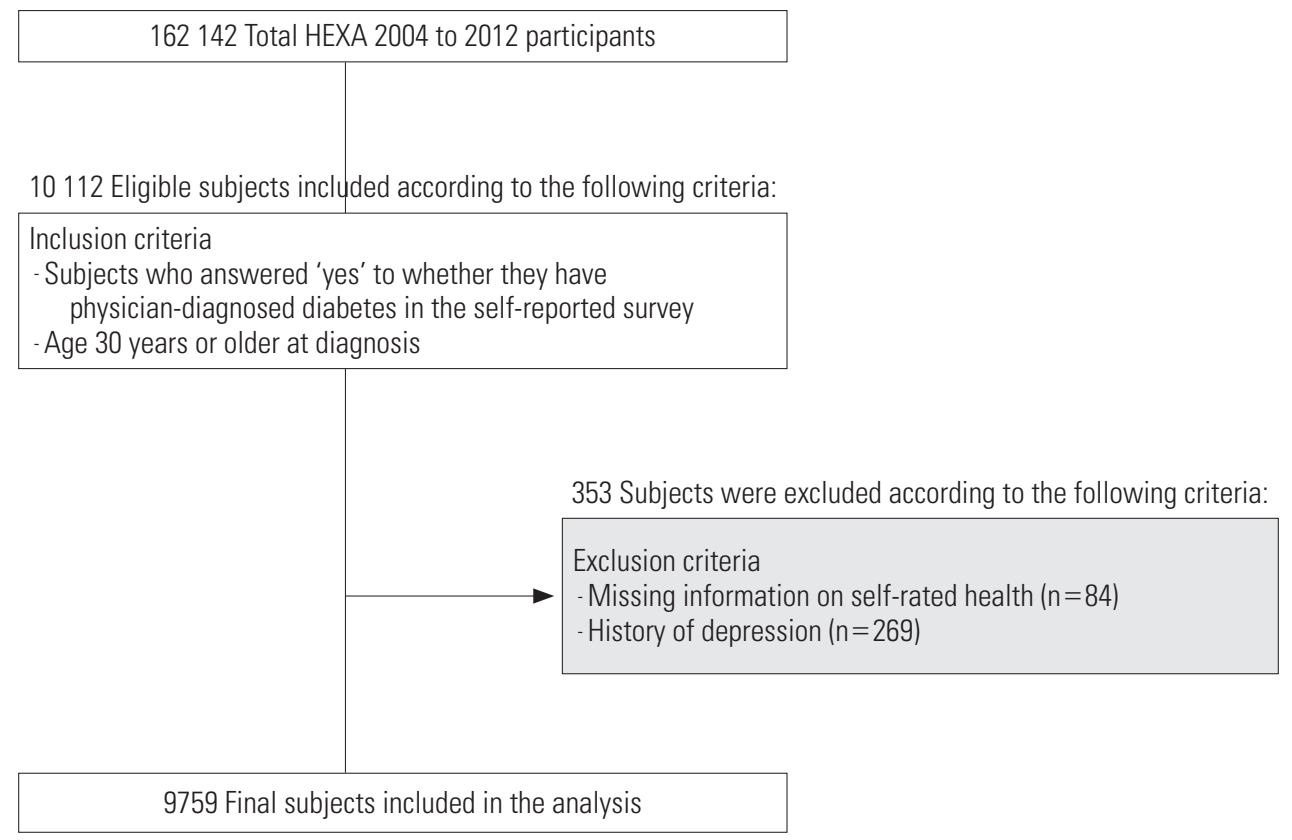

Figure 1. Flow diagram showing selection of study subjects. HEXA, Health Examinees. 
tory of depression ( $n=269)$. Since a number of studies has argued that depression is closely correlated with poor SRH, we excluded respondents with depression in order to eliminate the potential influence on the evaluation of SRH by depressed individuals in relation to variables of interest $[3,15]$. A total of 9759 respondents comprised the final subjects of our analysis (Figure 1).

\section{Self-rated Health}

SRH was assessed with a single question:'How do you evaluate your current health status?' Participants were asked to choose a response from a five-category Likert scale (very healthy, healthy, normal, unhealthy, or very unhealthy). Following common procedure, we grouped the answers into a dichotomous variable of 'good' (very healthy, healthy, and normal) and 'poor' (unhealthy and very unhealthy) [16].

\section{Domains of Health Determinants}

The factors presumed to be correlated with SRH were grouped into different domains: sociodemographic factors, lifestyle factors, psychosocial conditions, anthropometric indices, and physical conditions (Supplemental Table 1). The physical domain of health focused on diabetes history and status as well as comorbid conditions.

The sociodemographic factors included sex and age. Age was divided into intervals of 40 to 49 years, 50 to 59 years, and 60 to 69 years. Marital status was defined as married or not married. Educational attainment was classified as less than a high school diploma, a high school diploma to some college, or a bachelor's degree and higher. Occupation types were classified as non-manual labor, manual labor, and not in the work force. Income was categorized based on the monthly salary in units of 1000 Korean won $(<2000,2000$ to 4000 or $\geq 4000)$, which is approximately equivalent to units of 1 US dollar.

Lifestyle factors included smoking, alcohol consumption, and physical activity. Smoking status and alcohol consumption were classified as never, past, or current. The physical activity variable was defined by classifying participants as either regular exercisers or non-exercisers, where regular exercisers referred to those who engaged in regular, sweat-inducing exercise.

The psychosocial variables included the frequency of mental and/or physical stress experienced during the past month (not at all, sometimes, or frequent). The psychosocial well-being index (PWI), a measure of mental health focusing on the psychosocial aspect of stress $[17,18]$, was used to define three groups: positive well-being, moderate distress, and severe distress. Sleep duration was categorized as $<6,6$ to 8,8 to 10 or $\geq 10 \mathrm{~h} / \mathrm{d}$.

The anthropometric indices included body mass index (BMI) and waist circumference (WC). Respondents were classified into five BMI groups based on the weight range associated with a minimal risk of death in Asian populations: underweight $(<22.5$ $\mathrm{kg} / \mathrm{m}^{2}$ ), normal weight (22.6 to $25.0 \mathrm{~kg} / \mathrm{m}^{2}$ ), overweight ( 25.1 to $\left.27.1 \mathrm{~kg} / \mathrm{m}^{2}\right)$, pre-obese $\left(27.6\right.$ to $\left.30.0 \mathrm{~kg} / \mathrm{m}^{2}\right)$, or obese $(>30.0$ $\mathrm{kg} / \mathrm{m}^{2}$ ) [19]. Central obesity was defined as a $W C \geq 90 \mathrm{~cm}$ in men and $\geq 80 \mathrm{~cm}$ in women, as suggested by global organizations such as the International Diabetes Federation [20,21].

In the physical domain, subjects' diabetes history and status were queried and the following variables were extracted: age of diagnosis, duration of the disease, current treatment status, treatment type, fasting blood sugar (FBS) level, and hemoglobin A1c ( $\mathrm{HbA1c}$ ) level. The age of diagnosis was presented as a mean ( \pm standard deviation [SD]) value and was also divided into dichotomous groups of $<50$ vs. $\geq 50$ years [8]. The duration of diabetes was classified as $<5,5$ to 10 , or $\geq 10$ years. The current treatment status included no treatment necessary, currently under treatment, or treatment neglected or never treated. The treatment types were divided into lifestyle modification, oral medication, or insulin therapy. As an indicator of diabetes control, FBS was categorized into $<126 \mathrm{mg} / \mathrm{dL}$ vs. $\geq$ $126 \mathrm{mg} / \mathrm{dL}$. A subgroup analysis was conducted on subjects who provided information about their HbA1c levels $(n=3689)$. As an indicator of long-term diabetes control status, $\mathrm{HbA} 1 \mathrm{c}$ was categorized as $<6.5 \%$ vs. $\geq 6.5 \%$.

The HEXA Study surveyed information on participants' personal medical histories and medication usage. Based on selfreports, nine diseases and conditions were evaluated in our study: hypertension, hyperlipidemia, stroke, myocardial infarction, gastrointestinal diseases, liver diseases, diseases of the joints and bones, respiratory diseases, and cancer.

\section{Statistical Analysis}

Selected characteristics for the two SRH groups (good vs. poor) were compared using the Student's $t$-test for continuous variables and the chi-square test for categorical variables. All results were considered statistically significant at a $p$-value $<0.05$. Logistic regression analyses were performed to identify factors that were significantly associated with poor SRH. Odds ratios (ORs) and $95 \%$ confidence intervals ( $\mathrm{Cls}$ ) were calculated. Three models were included in the overall analysis. Model 1 was adjusted for sex and age. Model 2 was adjusted for so- 
Table 1. Basic characteristics of the study population ${ }^{1}(n=9759)$

\begin{tabular}{|c|c|c|}
\hline & $\mathbf{n}$ & $(\%)$ \\
\hline \multicolumn{3}{|l|}{ Sociodemographic factors } \\
\hline \multicolumn{3}{|l|}{ Sex } \\
\hline Male & 4721 & 48.4 \\
\hline Female & 5038 & 51.6 \\
\hline \multicolumn{3}{|l|}{ Age (y) } \\
\hline $40-49$ & 1339 & 13.7 \\
\hline $50-59$ & 3892 & 39.9 \\
\hline $60-69$ & 4528 & 46.4 \\
\hline \multicolumn{3}{|l|}{ Marital status ${ }^{2}$} \\
\hline Married & 8523 & 87.3 \\
\hline Not married & 1212 & 12.4 \\
\hline \multicolumn{3}{|l|}{ Educational attainment } \\
\hline Bachelor's degree or higher & 1768 & 18.1 \\
\hline High school diploma to college ${ }^{3}$ & 3414 & 35.0 \\
\hline Less than high school diploma & 4467 & 45.8 \\
\hline \multicolumn{3}{|l|}{ Occupation type } \\
\hline Non-manual labor & 1496 & 15.3 \\
\hline Manual labor & 3109 & 31.9 \\
\hline Not in work force ${ }^{4}$ & 4974 & 51.0 \\
\hline \multicolumn{3}{|l|}{ Income ${ }^{5}$} \\
\hline$\geq 4000$ & 1500 & 15.4 \\
\hline $2000-4000$ & 3020 & 31.0 \\
\hline$<2000$ & 3766 & 38.6 \\
\hline \multicolumn{3}{|l|}{ Lifestyle factors } \\
\hline Current smokers & 1532 & 15.7 \\
\hline Current drinkers & 4083 & 41.8 \\
\hline Regular exercisers & 5774 & 59.2 \\
\hline \multicolumn{3}{|l|}{ Psychosocial conditions } \\
\hline \multicolumn{3}{|l|}{ Stress events } \\
\hline Not at all & 5217 & 53.5 \\
\hline Often & 3505 & 35.9 \\
\hline Frequent & 936 & 9.6 \\
\hline PWI score (mean $\pm S D$, points) ${ }^{6}$ & 17 & 8.3 \\
\hline \multicolumn{3}{|l|}{ PWI status } \\
\hline Positive well-being & 1043 & 10.7 \\
\hline Moderate distress & 7121 & 73.0 \\
\hline Severe distress & 1274 & 13.1 \\
\hline \multicolumn{3}{|l|}{ Sleep duration $(\mathrm{h} / \mathrm{d})$} \\
\hline$<6$ & 1307 & 13.4 \\
\hline $6-8$ & 5603 & 57.4 \\
\hline $8-10$ & 2560 & 26.2 \\
\hline$\geq 10$ & 248 & 2.5 \\
\hline \multicolumn{3}{|l|}{ Anthropometry } \\
\hline BMI (mean $\left.\pm S D, k g / m^{2}\right)$ & 24.9 & 3.1 \\
\hline $\mathrm{WC}($ mean $\pm S D, \mathrm{~cm})$ & 85.6 & 8.4 \\
\hline
\end{tabular}

(Continued to the next)
Table 1. Continued

\begin{tabular}{lrr}
\hline & $\mathbf{n}$ & (\%) \\
\hline Indicators of DM control & & \\
FBS (mean \pm SD, mg/dL) & 134.1 & 44.7 \\
HbA1c (mean \pm SD, \%) & 7.3 & 1.4 \\
\hline
\end{tabular}

SD, standard deviation; SRH, self-rated health; PWI, psychosocial well-being; BMI, body mass index; WC, waist circumference; FBS, fasting blood sugar; $\mathrm{HbA1c}$, hemoglobin $\mathrm{A1C}$; DM, diabetes mellitus; SD, standard deviation.

'Unknown values are not shown, but were included in statistical models.

${ }^{2}$ Married includes married or living with a partner; not married includes single, divorced, separated, or widowed.

${ }^{3}$ College includes a vocational certificate, associate's degree, or some years of college-level education without completion of a degree.

${ }^{4}$ Not in work force refers to housewives, students, or the unemployed.

${ }^{5}$ Income refers to monthly salary in Korean won (unit: 1000 won).

${ }^{6} \mathrm{PWI}$ scores: $\leq 8$, positive well-being; 9-26, moderate distress; $\geq 27$, severe distress.

ciodemographic factors (sex, age, marital status, education level, employment status, and income level) and lifestyle factors (smoking status, alcohol consumption, and physical activity). Model 3 was adjusted for the covariates in model 2 as well as psychosocial conditions (stress events, PWI score, and sleep duration) and anthropometry (BMI and WC). All statistical analyses were performed using SAS version 9.4 (SAS Institute Inc., Cary, NC, USA).

\section{RESULTS}

The basic characteristics of the study subjects are presented in Table 1. Our study included more women (51.6\%) than men, and the older age group (60 to 69 years) comprised almost half of the diabetic population (46.4\%). Most of the subjects were married $(87.3 \%)$ and were not in the work force $(51.0 \%)$. The plurality of respondents were current drinkers (41.8\%), more than half (59.2\%) were regular exercisers, and $15.7 \%$ were smokers. Most of the subjects reported experiencing moderate distress (73.0\%), but more than half (53.5\%) of the subjects did not report mental and/or physical stress during the past month. Approximately $57 \%$ of the respondents slept six to eight hours per day on average. The mean \pm SD values of BMI and WC were $24.9 \pm 3.1 \mathrm{~kg} / \mathrm{m}^{2}$ and $85.6 \pm 8.4 \mathrm{~cm}$, respectively. The mean \pm SD FBS value was $134.1 \pm 44.7 \mathrm{mg} / \mathrm{dL}$ and the mean $\mathrm{HbA} 1 \mathrm{c}$ level was $7.3 \pm 1.4 \%$.

The ORs of poor SRH according to multiple domains of health determinants are presented in Table 2. Sociodemographic factors had a significant impact in the fully adjusted model, with the exception of income level. Poor SRH was significantly asso- 
Table 2. ORs ( $95 \% \mathrm{Cls}$ ) of poor SRH according to selected correlates of the study population ${ }^{1}(\mathrm{n}=9759)$

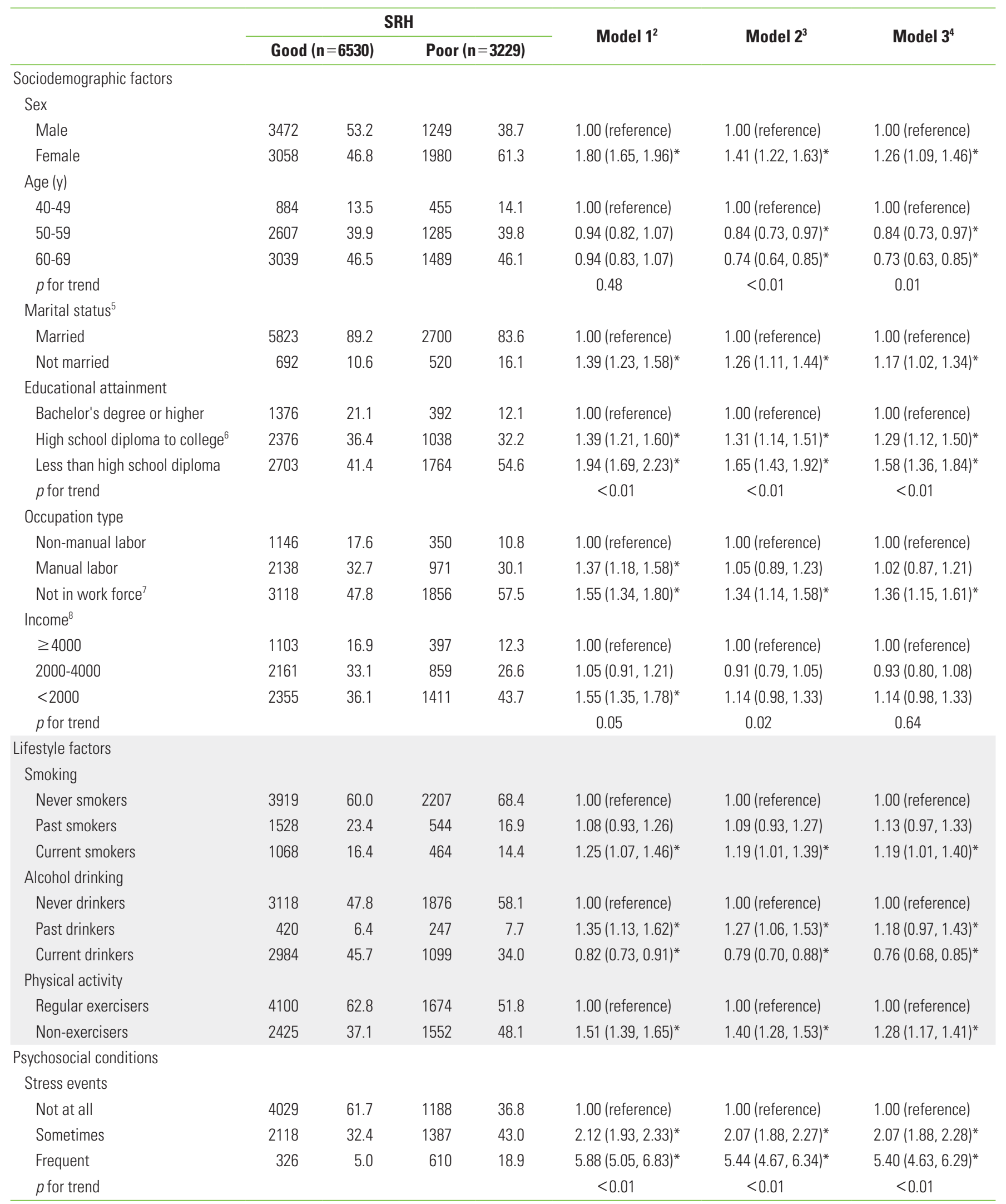


Table 2. Continued from the previous page

\begin{tabular}{|c|c|c|c|c|c|c|c|}
\hline & & & & & 18 & & \\
\hline & Good & 6530) & Poor & 3229) & Model $1^{2}$ & Model $2^{3}$ & Model $3^{4}$ \\
\hline & & & & & & & \\
\hline Positive well-being & 922 & 14.1 & 121 & 3.8 & 1.00 (reference) & 1.00 (reference) & 1.00 (reference) \\
\hline Moderate distress & 5042 & 77.2 & 2079 & 64.4 & $2.98(2.45,3.63)^{*}$ & $2.91(2.39,3.55)^{*}$ & $2.58(2.11,3.15)^{*}$ \\
\hline Severe distress & 357 & 5.5 & 917 & 28.4 & $17.92(14.29,22.48)^{*}$ & $15.95(12.69,20.04)^{*}$ & $11.08(8.77,14.00)^{*}$ \\
\hline$p$ for trend & & & & & $<0.01$ & $<0.01$ & $<0.01$ \\
\hline Sleep duration $(\mathrm{h} / \mathrm{d})$ & & & & & & & \\
\hline$<6$ & 802 & 12.3 & 505 & 15.6 & $1.37(1.21,1.56)^{*}$ & $1.31(1.15,1.48)^{*}$ & $1.17(1.03,1.34)^{*}$ \\
\hline $6-8$ & 3886 & 59.5 & 1717 & 53.2 & 1.00 (reference) & 1.00 (reference) & 1.00 (reference) \\
\hline $8-10$ & 1681 & 25.7 & 879 & 27.2 & $1.17(1.06,1.30)^{*}$ & $1.11(1.00,1.22)^{*}$ & $1.14(1.03,1.27)^{*}$ \\
\hline$\geq 10$ & 138 & 2.1 & 110 & 3.4 & $1.79(1.38,2.32)^{*}$ & $1.59(1.22,2.07)^{*}$ & $1.58(1.20,2.08)^{*}$ \\
\hline$p$ for trend & & & & & 0.18 & 0.34 & 0.26 \\
\hline Anthropometry & & & & & & & \\
\hline Body mass index $\left(\mathrm{kg} / \mathrm{m}^{2}\right)$ & & & & & & & \\
\hline Underweight ( $\leq 22.5$ ) & 1355 & 20.8 & 730 & 22.6 & $1.16(1.04,1.31)^{*}$ & $1.16(1.03,1.30)^{*}$ & $1.13(1.00,1.28)^{*}$ \\
\hline Normal (22.6-25.0) & 2267 & 34.7 & 1013 & 31.4 & 1.00 (reference) & 1.00 (reference) & 1.00 (reference) \\
\hline Overweight (25.1-27.5) & 1813 & 27.8 & 899 & 27.8 & $1.13(1.01,1.26)^{*}$ & $1.10(0.99,1.23)^{*}$ & $1.09(0.97,1.22)^{*}$ \\
\hline Pre-obese (27.5-30.0) & 757 & 11.6 & 359 & 11.1 & $1.05(0.90,1.21)$ & $1.01(0.87,1.18)$ & $0.98(0.84,1.15)$ \\
\hline Obese $(>30.0)$ & 326 & 5 & 219 & 6.8 & $1.38(1.14,1.67)^{*}$ & $1.29(1.06,1.56)^{*}$ & $1.22(1.00,1.49)^{*}$ \\
\hline WC & & & & & & & \\
\hline No central obesity & 3090 & 47.3 & 1367 & 42.3 & 1.00 (reference) & 1.00 (reference) & 1.00 (reference) \\
\hline Central obesity ${ }^{10}$ & 3309 & 50.7 & 1774 & 54.9 & $1.07(0.98,1.17)$ & $1.00(0.91,1.09)$ & $1.02(0.91,1.15)$ \\
\hline
\end{tabular}

Values are presented as number (\%) or OR (95\% Cl).

$\mathrm{SRH}$, self-rated health; PWI, psychosocial well-being; BMI, body mass index; WC, waist circumference; OR, odds ratio; Cl, confidence interval.

'Unknown values are not shown, but were included in statistical models.

${ }^{2}$ Model 1, adjusted for sex and age.

${ }^{3}$ Model 2, adjusted for sociodemographic factors (sex, age, marital status, education level, employment status, and income level) and lifestyle factors (smoking status, alcohol consumption, and physical activity).

${ }^{4}$ Model 3, fully adjusted for sociodemographic factors (sex, age, marital status, education level, employment status, and income level), lifestyle factors (smoking status, alcohol consumption, and physical activity), psychosocial conditions (stress events, PWI score, and sleep duration), and anthropometry (BMI and WC).

${ }^{5}$ Married includes married or living with a partner; not married includes single, divorced, separated, or widowed.

${ }^{6}$ College includes a vocational certificate, associate's degree, or some years of college-level education without completion of a degree.

${ }^{7}$ Not in work force refers to housewives, students, or the unemployed.

${ }^{8}$ Income refers to monthly salary in Korean won (unit: 1000 won).

${ }^{9} \mathrm{PWI}$ scores: $\leq 8$, positive well-being; 9-26, moderate distress; $\geq 27$, severe distress.

${ }^{10} \mathrm{Central}$ obesity refers to a waist circumference of $\geq 90 \mathrm{~cm}$ in men and $\geq 80 \mathrm{~cm}$ in women.

${ }^{*} p<0.05$.

ciated with female gender (OR, 1.26; 95\% Cl, 1.09 to 1.46), not being married or living with a partner $(\mathrm{OR}, 1.17 ; 95 \% \mathrm{Cl}, 1.02$ to 1.34), and unemployment (OR, 1.36; $95 \% \mathrm{Cl}, 1.15$ to 1.61$)$. The most prominent association was observed with educational attainment, as the likelihood of reporting poor SRH increased with a lower level of education ( $p$ for trend $<0.01$ ). The lifestyle factors of smoking and lack of regular physical activity were also significantly associated with increased odds of poor SRH. Age and alcohol, however, were inversely associated with poor SRH, with the odds of poor SRH gradually decreasing in older age groups ( $p$ for trend $=0.01$ ). Psychosocial conditions such as frequent stress events and severe distress, based on PWI scores, showed the strongest associations with poor SRH, with frequent stress events accounting for a 5.40-fold increase in the odds of poor SRH ( $95 \% \mathrm{Cl}, 4.63$ to 6.29 ) and severe distress being associated with an 11.08-fold increase in the odds of poor $\mathrm{SRH}$ ( $95 \% \mathrm{Cl}, 8.77$ to 14.00$)$, even after full adjustment for covariates. While stress events and PWI status were associated with higher odds of poor SRH ( $p$ for trend $<0.01$ ), sleep duration showed a J-shaped association with poor SRH. BMI presented a U-shaped association, in which subjects at both ends of the BMI spectrum (underweight and obese) were marginally 
Table 3. ORs (95\% Cls) for poor SRH according to diabetes history, diabetes status, and comorbidity status ${ }^{1}(\mathrm{n}=9759)$

\begin{tabular}{|c|c|c|c|c|c|c|c|}
\hline & \multicolumn{4}{|c|}{ SRH } & \multirow{2}{*}{ Model $1^{2}$} & \multirow{2}{*}{ Model $2^{3}$} & \multirow{2}{*}{ Model $3^{4}$} \\
\hline & \multicolumn{2}{|c|}{$\operatorname{Good}(n=6530)$} & \multicolumn{2}{|c|}{ Poor (n=3229) } & & & \\
\hline \multicolumn{8}{|l|}{ Diabetes history and status } \\
\hline \multicolumn{8}{|l|}{ DM diagnosis age (y) } \\
\hline$\geq 50$ & 4123 & 63.1 & 1875 & 58.1 & 1.00 (reference) & 1.00 (reference) & 1.00 (reference) \\
\hline$<50$ & 2407 & 36.9 & 1354 & 41.9 & $1.38(1.24,1.54)^{*}$ & $1.42(1.27,1.58)^{*}$ & $1.46(1.30,1.63)^{*}$ \\
\hline \multicolumn{8}{|l|}{ DM duration (y) } \\
\hline$<5$ & 2593 & 39.7 & 1083 & 33.5 & 1.00 (reference) & 1.00 (reference) & 1.00 (reference) \\
\hline $5-10$ & 1632 & 25.0 & 821 & 25.4 & $1.21(1.08,1.35)^{*}$ & $1.23(1.10,1.38)^{*}$ & $1.27(1.14,1.44)^{*}$ \\
\hline$\geq 10$ & 1564 & 24.0 & 950 & 29.4 & $1.52(1.36,1.70)^{*}$ & $1.55(1.39,1.74)^{*}$ & $1.62(1.44,1.82)^{*}$ \\
\hline Unknown & 741 & 11.4 & 375 & 11.6 & & & \\
\hline \multicolumn{8}{|l|}{ Current treatment status } \\
\hline No treatment necessary & 174 & 2.7 & 48 & 1.5 & 1.00 (reference) & 1.00 (reference) & 1.00 (reference) \\
\hline Currently under treatment & 5523 & 84.6 & 2827 & 87.6 & $1.91(1.38,2.64)^{*}$ & $2.03(1.46,2.82)^{*}$ & $2.03(1.44,2.85)^{*}$ \\
\hline Treatment neglected/never treated & 833 & 12.8 & 354 & 11.0 & $1.61(1.14,2.28)^{*}$ & $1.66(1.17,2.35)^{*}$ & $1.58(1.10,2.27)^{*}$ \\
\hline \multicolumn{8}{|l|}{ Treatment type ${ }^{5}$} \\
\hline Lifestyle modification only ${ }^{6}$ & 157 & 2.8 & 57 & 2.0 & 1.00 (reference) & 1.00 (reference) & 1.00 (reference) \\
\hline Oral meds \pm lifestyle & 4009 & 72.6 & 1798 & 63.6 & $1.22(0.89,1.66)$ & $1.17(0.85,1.60)$ & $1.26(0.91,1.76)$ \\
\hline Insulin \pm oral meds \pm lifestyle & 234 & 4.2 & 228 & 8.1 & $2.65(1.86,3.79)^{*}$ & $2.43(1.69,3.50)^{*}$ & $2.62(1.79,3.82)^{*}$ \\
\hline Unknown & 1123 & 20.3 & 744 & 26.3 & & & \\
\hline \multicolumn{8}{|l|}{ Fasting blood sugar (mg/dL) } \\
\hline$<126$ & 3353 & 51.4 & 1628 & 50.4 & 1.00 (reference) & 1.00 (reference) & 1.00 (reference) \\
\hline$\geq 126$ & 3025 & 46.3 & 1539 & 47.7 & $1.07(0.98,1.17)$ & $1.08(0.99,1.18)$ & $1.08(0.99,1.18)$ \\
\hline Unknown & 152 & 2.3 & 62 & 1.9 & & & \\
\hline \multicolumn{8}{|l|}{ Comorbidity status } \\
\hline \multicolumn{8}{|l|}{ Comorbid diseases ${ }^{7}$} \\
\hline Hypertension & 2560 & 39.2 & 1508 & 46.7 & $1.37(1.26,1.50)^{*}$ & $1.41(1.29,1.54)^{*}$ & $1.46(1.33,1.61)^{*}$ \\
\hline Hyperlipidemia & 786 & 12.0 & 561 & 17.4 & $1.45(1.29,1.64)^{*}$ & $1.57(1.39,1.78)^{*}$ & $1.57(1.38,1.78)^{*}$ \\
\hline Stroke & 77 & 1.2 & 90 & 2.8 & $2.76(2.02,3.77)^{*}$ & $2.57(1.87,3.52)^{*}$ & $2.57(1.85,3.57)^{*}$ \\
\hline Myocardial infarction & 247 & 3.8 & 220 & 6.8 & $2.10(1.73,2.54)^{*}$ & $2.10(1.73,2.55)^{*}$ & $2.03(1.65,2.48)^{*}$ \\
\hline Gastrointestinal diseases & 94 & 1.4 & 115 & 3.6 & $2.50(1.89,3.31)^{*}$ & $2.48(1.87,3.29)^{*}$ & $2.25(1.68,3.02)^{*}$ \\
\hline Liver diseases & 147 & 1.5 & 124 & 1.3 & $1.87(1.46,2.39)^{*}$ & $1.87(1.46,2.40)^{*}$ & $1.78(1.37,2.31)^{*}$ \\
\hline Diseases of the joints and bones & 279 & 4.3 & 330 & 10.2 & $2.18(1.84,2.59)^{*}$ & $2.11(1.77,2.50)^{*}$ & $1.98(1.66,2.37)^{*}$ \\
\hline Respiratory diseases & 40 & 0.6 & 38 & 1.2 & $2.22(1.41,3.48)^{*}$ & $1.89(1.19,2.98)^{*}$ & $1.69(1.06,2.71)^{*}$ \\
\hline Cancer & 61 & 0.9 & 58 & 1.8 & $1.93(1.34,2.78)^{*}$ & $1.83(1.26,2.65)^{*}$ & $1.85(1.26,2.71)^{*}$ \\
\hline \multicolumn{8}{|l|}{ No. of diseases } \\
\hline None (DM only) & 3263 & 50.0 & 1208 & 37.4 & 1.00 (reference) & 1.00 (reference) & 1.00 (reference) \\
\hline DM+one condition & 2416 & 37.0 & 1225 & 37.9 & $1.39(1.26,1.53)^{*}$ & $1.42(1.29,1.57)^{*}$ & $1.48(1.33,1.64)^{*}$ \\
\hline DM+two or more conditions & 851 & 13.0 & 796 & 24.7 & $2.54(2.25,2.86)^{*}$ & $2.65(2.34,3.00)^{*}$ & $2.69(2.36,3.07)^{*}$ \\
\hline$p$ for trend & & & & & $<0.01$ & $<0.01$ & $<0.01$ \\
\hline
\end{tabular}

Values are presented as number (\%) or OR (95\% Cl).

$\mathrm{SRH}$, self-rated health; DM, diabetes mellitus; OR, odds ratio; Cl, confidence interval.

${ }^{1}$ Unless the values comprised a significant percentage of the total, unknown values are not shown, but were included in the statistical models.

${ }^{2}$ Model 1, adjusted for sex and age.

${ }^{3}$ Model 2, adjusted for sociodemographic factors (sex, age, marital status, education level, employment status, and income level) and lifestyle factors (smoking status, alcohol consumption, and physical activity).

${ }^{4}$ Model 3, fully adjusted for sociodemographic factors (sex, age, marital status, education level, employment status, and income level), lifestyle factors (smoking status, alcohol consumption, and physical activity), psychosocial conditions (stress events, PWI score, and sleep duration), and anthropometry (body mass index and waist circumference).

${ }^{5}$ Treatment type refers to those categorized as 'currently under treatment'.

${ }^{6}$ Lifestyle modification only refers to diet and/or exercise regimens.

${ }^{7}$ Gastrointestinal diseases include ulcer diseases and chronic gastritis; liver diseases include acute, chronic, and fatty liver disease; diseases of the joints and bones include arthritis and osteoporosis; respiratory diseases include asthma and pulmonary tuberculosis.

${ }^{*} p<0.05$. 
Table 4. ORs (95\% Cls) for poor SRH according to HbA1c as an indicator of long-term DM control $(n=3689)$

\begin{tabular}{|c|c|c|c|c|c|c|c|}
\hline \multirow{3}{*}{ Indicator of long-term DM contro } & \multicolumn{4}{|c|}{ SRH } & \multirow{2}{*}{ Model $1^{1}$} & \multirow{2}{*}{ Model $2^{2}$} & \multirow{2}{*}{ Model $3^{3}$} \\
\hline & \multicolumn{2}{|c|}{$\operatorname{Good}(n=2576)$} & \multicolumn{2}{|c|}{ Poor $(n=1113)$} & & & \\
\hline & & & & & & & \\
\hline $\mathrm{HbA1c}($ mean \pm SD) & 7.2 & 1.3 & 7.4 & 1.5 & $1.13(1.08,1.19)^{*}$ & $1.11(1.05,1.17)^{*}$ & $1.11(1.06,1.17)^{*}$ \\
\hline \multicolumn{8}{|l|}{$\mathrm{HbA} 1 \mathrm{c}(\%)$} \\
\hline$<6.5$ & 812 & 31.5 & 294 & 26.4 & 1.00 (reference) & 1.00 (reference) & 1.00 (reference) \\
\hline$\geq 6.5$ & 1764 & 68.5 & 819 & 73.6 & $1.24(1.06,1.45)^{*}$ & $1.21(1.04,1.43)^{*}$ & $1.21(1.02,1.43)^{*}$ \\
\hline
\end{tabular}

Values are presented as number (\%) or odds ratio (95\% Cl).

$\mathrm{SRH}$, self-rated health; DM, diabetes mellitus; HbA1c, hemoglobin A1c; OR, odds ratio; Cl, confidence interval; SD, standard deviation.

${ }^{1}$ Model 1 , adjusted for sex and age.

${ }^{2}$ Model 2, adjusted for sociodemographic factors (sex, age, marital status, education level, employment status, and income level) and lifestyle factors (smoking status, alcohol consumption, and physical activity).

${ }^{3}$ Model 3, fully adjusted for sociodemographic factors (sex, age, marital status, education level, employment status, and income level), lifestyle factors (smoking status, alcohol consumption, and physical activity), psychosocial conditions (stress events, PWI score, and sleep duration), and anthropometry (body mass index and waist circumference).

${ }^{*} p<0.05$.

more likely to report poor SRH (ORunderweight, $1.13 ; 95 \% \mathrm{Cl}, 1.00$ to 1.28 , ORobese, $1.22 ; 95 \% \mathrm{Cl}, 1.00$ to 1.49 ).

The details of the associations between poor SRH and physical health variables dealing with participants' medical history of diabetes and comorbidities are shown in Table 3. FBS did not show a significant association with poor $\mathrm{SRH}$, but a younger age at the time of diagnosis, a diabetes duration of 5 to 10 years and $\geq 10$ years, current treatment, and receiving insulin therapy were all variables found to be significantly associated with increased odds of poor SRH. In fact, a 1.46-fold increased likelihood of poor SRH was found in subjects who were diagnosed at a younger age $(95 \% \mathrm{Cl}, 1.30$ to 1.63$)$, and ORs of 1.27 $(95 \% \mathrm{Cl}, 1.14$ to 1.44$)$ and $1.62(95 \% \mathrm{Cl}, 1.44$ to 1.82$)$ were found in respondents with diabetes durations of 5 to 10 years and $\geq 10$ years, respectively. Compared to subjects for whom treatment was unnecessary, respondents currently undergoing treatment $(\mathrm{OR}, 2.03 ; 95 \% \mathrm{Cl}, 1.44$ to 2.85$)$ and having never received treatment or having neglected their treatment (OR, $1.58 ; 95 \% \mathrm{Cl}, 1.10$ to 2.27 ) had higher odds of poor SRH. Respondents who received insulin therapy in addition to oral medication and/or lifestyle modification had a higher likelihood of poor SRH (OR, 2.62; $95 \% \mathrm{Cl}, 1.79$ to 3.82) compared to those who engaged in lifestyle modification only.

A significant association was found between each comorbid condition and poor SRH (Table 3). Diseases associated with a higher likelihood of poor health were stroke $(\mathrm{OR}, 2.57 ; 95 \% \mathrm{Cl}$, 1.85 to 3.57$)$, gastrointestinal diseases $(\mathrm{OR}, 2.25 ; 95 \% \mathrm{Cl}, 1.68$ to $3.02)$, and myocardial infarction (OR, $2.03 ; 95 \% \mathrm{Cl}, 1.65$ to 2.48$)$. Additionally, the odds of poor SRH increased as the number of comorbid conditions increased ( $p$ for trend $<0.01$ ).
A subgroup analysis was conducted on 3689 subjects who provided information about their HbA1c levels (Table 4). Compared to the reference group with an $\mathrm{HbA} 1 \mathrm{c}$ level $<6.5 \%$, those with higher $\mathrm{HbA1c}$ levels had increased odds of poor $\mathrm{SRH}(\mathrm{OR}, 1.21 ; 95 \% \mathrm{Cl}, 1.02$ to 1.43$)$.

\section{DISCUSSION}

The present study was conducted to explore various domains of health determinants possibly associated with poor SRH among diabetic adults in Korea. After adjusting for sociodemographic, lifestyle, psychosocial factors, and anthropometric indices, the associations between poor SRH and a number of characteristics remained statistically significant. Specifically, the psychosocial domain of health, including stress events and PWI scores, were observed to have greater impact on SRH than other types of health determinants. Factors such as low sociodemographic status, adverse lifestyle behaviors, and disease history were also significantly associated with poor SRH.

In our study of the Korean diabetic population, variables representative of psychosocial distress were found to be strongly associated with an increased likelihood of poor SRH. These results are consistent with prior studies of diabetic populations in other nations demonstrating SRH to be strongly related to emotional well-being $[15,22]$. The strong association between poor SRH and psychological measures may be due to reasons specific to the diabetic population, since emotional distress occurs as a result of the severity of diabetes and the resulting burden of self-care [23]. When dealing with the demands of the disease, many people with diabetes may become emotionally 
overwhelmed, frustrated, and discouraged - an emotional reaction now understood as diabetes-related distress [24]. In a study by Jones et al. [25] of people with diabetes, approximately half of the study subjects (50.1\%) reported that living with diabetes took up too much mental and physical energy every day. In a study conducted by de Groot et al. [26], reduced wellbeing and mental health problems were found to be more prevalent among people with type 2 diabetes than in the general population.

Certain sociodemographic factors, such as younger age, female gender, and low educational attainment, were also associated with poor SRH, echoing the findings of prior studies on diabetic populations [23,27-29]. The positive association between poor SRH and younger age deserves particular attention because the opposite association is observed in the general population [12]. This phenomenon may be explained in several ways. First, the notion of social comparison explains that older people are more likely to normalize physical discomfort by attributing it to aging rather than poor health [30]. Second, experiences and perceptions of diabetes differ by age, and the physical and psychological burdens appear to be generally greater in middle-aged subjects, even though older diabetic patients tend to have poorer control of the disease [31]. Our subgroup analyses (data not shown) showed that the oldest age group (60 to 69 years) had the greatest number of comorbidities. The middle-aged group (40 to 49 years) had the least overall prevalence of disease, but the highest odds of poor SRH.

Another finding in our diabetic population was that past drinkers had higher odds of poor SRH. Badawi et al. [3] proposed that never or past drinkers who are diabetic abstain from alcohol due to health reasons. In fact, we found in a separate analysis (data not shown) that never or past drinkers were more likely than current drinkers to have been undergoing current treatment, receiving insulin therapy, to have had diabetes for more than 10 years, and to have had more than one comorbid condition $(p<0.01)$. They also had significantly higher mean $\mathrm{HbA1c}$ levels, which reflect the severity of diabetes.

The physical domain of health was strongly associated with $\mathrm{SRH}$. Of a range of variables addressing participants' medical history and diabetes status, all except FBS were significantly associated with SRH. Our findings are supported by those of a prior study of diabetic patients, in which disease severity, including insulin use (OR, 2.0; $95 \% \mathrm{Cl}, 1.7$ to 2.3$)$ and a duration of diabetes of $\geq 20$ years ( $\mathrm{OR}, 1.3 ; 95 \% \mathrm{Cl}, 1.1$ to 1.6$)$, was as- sociated with an increased likelihood of fair or poor health [29]. Likewise, another study reported that one in five people with diabetes responded that taking diabetes medication interfered with their ability to live a normal life, resulting in a greater distress or a negative evaluation of their emotional well-being [25]. Moreover, Delahanty et al. [23] showed that compared to those who received diet or oral medication therapy, patients who underwent insulin therapy scored the highest in the assessment of diabetes-related emotional distress (Problem Areas in Diabetes scale (points \pm SD): 14.6 \pm 1.7 [diet] vs. $18.6 \pm 1.3$ [oral medication] vs. $23.6 \pm 1.7$ [insulin]).

Comorbid conditions were also found to be positively associated with poor SRH to varying extents. Moreover, this association strengthened as the number of comorbidities increased. An association between comorbidities and the odds of poor $\mathrm{SRH}$ has also been found in another diabetic population (OR, $4.3 ; 95 \% \mathrm{Cl}$, not shown) [28].

Since a limited number of studies have been published evaluating SRH in diabetic populations, we could not contextualize some of our results, including the role of sleep duration and marital status as health determinants of poor SRH specific to people with diabetes. We found that our results regarding sleep duration were not significantly different from studies based on the general population in Korea [12] and Australia [32], which found positive associations between poor SRH and short and long sleep durations. Not being married is also a significant correlate of poor SRH that may not be specific to the diabetic population [33,34]. However, Zheng and Thomas [35] pointed out the possibility of married people misestimating their health status in the positive direction; caution is thus warranted when interpreting SRH according to marital status. Further studies are needed to clarify the association between marital status and poor SRH. The adverse lifestyle behaviors of smoking and being physically inactive were also significantly associated with poor SRH, which is consistent both with studies on diabetic populations and with studies of the general population $[2,3,28,29]$.

Marginally significant associations were found between poor SRH and both underweight and obese status. Studies of nonAsian populations have failed to find an association between poor SRH and low BMl; in those studies, fair or poor health was only found to be related to obesity $[3,28,29]$. A possible explanation for this discrepancy is that insulin resistance in Asian populations occurs at a BMI level considered to be within the normal range for Western populations (23.0 to $24.0 \mathrm{~kg} / \mathrm{m}^{2}$ ) [36]. 
Japanese researchers showed that underweight $(\mathrm{BMI}<18.5$ $\mathrm{kg} / \mathrm{m}^{2}$ ) was associated with a 1.32-fold increased risk of diabetes in older males ( $95 \% \mathrm{Cl}, 1.12$ to 1.56 ) and a 1.31-fold increase in older females $(95 \% \mathrm{Cl}, 1.07$ to 1.60$)$ [37]. Moreover, weight loss is a symptom of diabetes [38]. The question of whether low BMI is associated with poor SRH as a symptom reflecting disease severity remains unresolved.

All of our variables-dependent and independent-were obtained from self-reported data, which may have compromised the validity due to recall bias. It is also important to keep in mind that the direction of causality could not be determined due to the cross-sectional nature of the present study.

Despite these limitations, our study has the strength of including a large sample of diabetic subjects. Using the HEXA questionnaire, we were able to conduct a comprehensive analysis of SRH by assessing a broad range of factors, from sociodemographic variables to physical health. Moreover, as this is one of the few studies of SRH and diabetes in the Korean population, the findings of this study add to our understanding of the association between low SRH and diabetes in a developed, non-Western society. Lastly, we limited our subjects to type 2 diabetic patients in order to identify the factors associated with negative perceptions of health among people with a specific health condition.

$\mathrm{SRH}$ is a widely used tool that is a strong predictor for mortality and morbidity, even in relation to diabetes [27,39]. In the present study, we identified factors with a significant relationship to poor SRH among the adult diabetic population in Korea. Although caution is warranted in interpreting the results, we found that multiple domains of health determinants were associated with poor SRH, most notably the psychosocial domain. Further studies are needed to investigate the underlying mechanisms connecting the psychosocial conditions, known variables, and unmeasured residual variables with SRH.

Negative perceived health status itself elicits adverse health outcomes in conditions such as diabetes. In our study, several domains of health determinants, ranging from sociodemographic to psychosocial and physical, were associated with poor SRH. Our findings suggest that younger age, underweight or obesity, and adverse psychosocial conditions could be factors that distinctively predict negative perceived health status in Korean adults with diabetes. As these factors may contribute both directly and indirectly to the exacerbation of diabetes via SRH, further studies are needed to explore the underlying mechanism. Meanwhile, strategies such as focus- ing attention on specific groups (middle-aged and/or underweight and obese adults) or routinely screening for stress may be suggested to improve the SRH —and eventually the overall prognosis - of people with diabetes.

\section{ACKNOWLEDGEMENTS}

This study was supported by the National Genome Research Institute, Korea Centers for Disease Control and Prevention. The authors would like to thank all participants and members of the HEXA Study Group.

\section{CONFLICT OF INTEREST}

The authors have no conflicts of interest associated with the material presented in this paper.

\section{REFERENCES}

1. Miilunpalo S, Vuori I, Oja P, Pasanen M, Urponen H. Self-rated health status as a health measure: the predictive value of selfreported health status on the use of physician services and on mortality in the working-age population. J Clin Epidemiol 1997;50(5):517-528.

2. Han MA, Kim KS, Park J, Kang MG, Ryu SY. Association between levels of physical activity and poor self-rated health in Korean adults: the Third Korea National Health and Nutrition Examination Survey (KNHANES), 2005. Public Health 2009;123(10): 665-669.

3. Badawi G, Gariépy G, Pagé V, Schmitz N. Indicators of self-rated health in the Canadian population with diabetes. Diabet Med 2012;29(8):1021-1028.

4. Mavaddat N, Parker RA, Sanderson S, Mant J, Kinmonth AL. Relationship of self-rated health with fatal and non-fatal outcomes in cardiovascular disease: a systematic review and meta-analysis. PLoS One 2014;9(7):e103509.

5. DeSalvo KB, Bloser N, Reynolds K, He J, Muntner P. Mortality prediction with a single general self-rated health question. A meta-analysis. J Gen Intern Med 2006;21(3):267-275.

6. Organization for Economic Cooperation and Development (OECD). Health at a Glance 2013: OECD indicators [cited 2015 Nov 17]. Available from: http://www.oecd.org/els/health-systems/Health-at-a-Glance-2013.pdf.

7. World Diabetes Foundation; International Diabetes Federation. Diabetes atlas. 6th ed. Brussels: IDF Executive Office; 


\section{3, p. 32-49.}

8. Korean Diabetes Association. Diabetes fact sheet in Korea 2013 [cited 2015 Nov 17]. Available from: http://www.diabetes.or.kr/ temp/diabetes_factsheet_2013111.pdf.

9. Shin HY, Shin MH, Rhee JA. Gender differences in the association between self-rated health and hypertension in a Korean adult population. BMC Public Health 2012;12:135.

10. Khang YH, Kim HR. Gender differences in self-rated health and mortality association: role of pain-inducing musculoskeletal disorders. J Womens Health (Larchmt) 2010;19(1):109-116.

11. Park JH, Lee KS. Self-rated health and its determinants in Japan and South Korea. Public Health 2013;127(9):834-843.

12. Kim JH, Kim KR, Cho KH, Yoo KB, Kwon JA, Park EC. The association between sleep duration and self-rated health in the Korean general population. J Clin Sleep Med 2013;9(10):10571064.

13. Health Examinees Study Group. The Health Examinees (HEXA) study: rationale, study design and baseline characteristics. Asian Pac J Cancer Prev 2015;16(4):1591-1597.

14. Onitilo AA, Stankowski RV, Berg RL, Engel JM, Williams GM, Doi $S A$. A novel method for studying the temporal relationship between type 2 diabetes mellitus and cancer using the electronic medical record. BMC Med Inform Decis Mak 2014;14:38.

15. Boehme S, Geiser C, Renneberg B. Functional and self-rated health mediate the association between physical indicators of diabetes and depressive symptoms. BMC Fam Pract 2014;15: 157.

16. Manor O, Matthews S, Power C. Dichotomous or categorical response? Analysing self-rated health and lifetime social class. Int J Epidemiol 2000;29(1):149-157.

17. Korean Society for Preventive Medicine, editors. Standardization of collection and measurement of health statistics data. Seoul: Gyechuk Munwhasa; 2000, p. 92-143 (Korean).

18. Song M, Hong YC, Cheong HK, Ha M, Kwon H, Ha EH, et al. Psychological health in residents participating in clean-up works of Hebei Spirit oil spill. J Prev Med Public Health 2009;42(2): 82-88 (Korean).

19. Zheng W, McLerran DF, Rolland B, Zhang X, Inoue M, Matsuo K, et al. Association between body-mass index and risk of death in more than 1 million Asians. N Engl J Med 2011;364(8):719729.

20. Alberti KG, Zimmet P, Shaw J; IDF Epidemiology Task Force Consensus Group. The metabolic syndrome-a new worldwide definition. Lancet 2005;366(9491):1059-1062.

21. World Health Organization Western Pacific Region. The Asia-
Pacific perspective: redefining obesity and its treatment. Melbourne: Health Communications Australia; 2000, p. 15-21.

22. Fatma HG, Joan VA, Ajabshir S, Gustavo ZG, Exebio J, Dixon Z. Perceived stress and self-rated health of Haitian and African Americans with and without type 2 diabetes. J Res Med Sci 2013;18(3):198-204.

23. Delahanty LM, Grant RW, Wittenberg E, Bosch JL, Wexler DJ, Cagliero E, et al. Association of diabetes-related emotional distress with diabetes treatment in primary care patients with type 2 diabetes. Diabet Med 2007;24(1):48-54.

24. Polonsky WH, Fisher L, Earles J, Dudl RJ, Lees J, Mullan J, et al. Assessing psychosocial distress in diabetes: development of the diabetes distress scale. Diabetes Care 2005;28(3):626-631.

25. Jones A, Olsen MZ, Perrild HJ, Willaing I. The psychological impact of living with diabetes: descriptive findings from the DAWN2 study in Denmark. Prim Care Diabetes 2015. http:// dx.doi.org/10.1016/j.pcd.2015.03.008.

26. de Groot M, Kushnick M, Doyle T, Merrill J, McGlynn M, Shubrook J, et al. Depression among adults with diabetes: prevalence, impact, and treatment options. Diabetes Spectr 2010; 23(1):15-18.

27. Wennberg P, Rolandsson O, Jerden L, Boeing H, Sluik D, Kaaks $\mathrm{R}$, et al. Self-rated health and mortality in individuals with diabetes mellitus: prospective cohort study. BMJ Open 2012;2(1): e000760.

28. Jimenez-Garcia R, Jimenez-Trujillo I, Hernandez-Barrera V, Carrasco-Garrido P, Lopez A, Gil A. Ten-year trends in self-rated health among Spanish adults with diabetes, 1993 2003. Diabetes Care 2008;31(1):90-92.

29. Self-rated fair or poor health among adults with diabetes--United States, 1996-2005. MMWR Morb Mortal Wkly Rep 2006; 55(45):1224-1227.

30. Tornstam L. Health and self-perception: a systems theoretical approach. Gerontologist 1975;15(3):264-270.

31. Wexler DJ, Porneala B, Chang Y, Huang ES, Huffman JC, Grant RW. Diabetes differentially affects depression and self-rated health by age in the U.S. Diabetes Care 2012;35(7):1575-1577.

32. Magee CA, Caputi P, Iverson DC. Relationships between selfrated health, quality of life and sleep duration in middle aged and elderly Australians. Sleep Med 2011;12(4):346-350.

33. Rohrer JE, Bernard ME, Zhang Y, Rasmussen NH, Woroncow $\mathrm{H}$. Marital status, feeling depressed and self-rated health in rural female primary care patients. J Eval Clin Pract 2008;14(2):214217.

34. Liu H, Umberson DJ. The times they are a changin: marital sta- 
tus and health differentials from 1972 to 2003. J Health Soc Behav 2008;49(3):239-253.

35. Zheng $\mathrm{H}$, Thomas PA. Marital status, self-rated health, and mortality: overestimation of health or diminishing protection of marriage? J Health Soc Behav 2013;54(1):128-143.

36. Raji A, Seely EW, Arky RA, Simonson DC. Body fat distribution and insulin resistance in Healthy Asian Indians and Caucasians. J Clin Endocrinol Metab 2001;86(11):5366-5371.

37. Sairenchi T, Iso H, Irie F, Fukasawa N, Ota H, Muto T. Underweight as a predictor of diabetes in older adults: a large cohort study. Diabetes Care 2008;31(3):583-584.

38. Report of the expert committee on the diagnosis and classification of diabetes mellitus. Diabetes Care 2003;26 Suppl 1:S5S20.

39. Hayes AJ, Clarke PM, Glasziou PG, Simes RJ, Drury PL, Keech AC. Can self-rated health scores be used for risk prediction in patients with type 2 diabetes? Diabetes Care 2008;31(4):795797. 


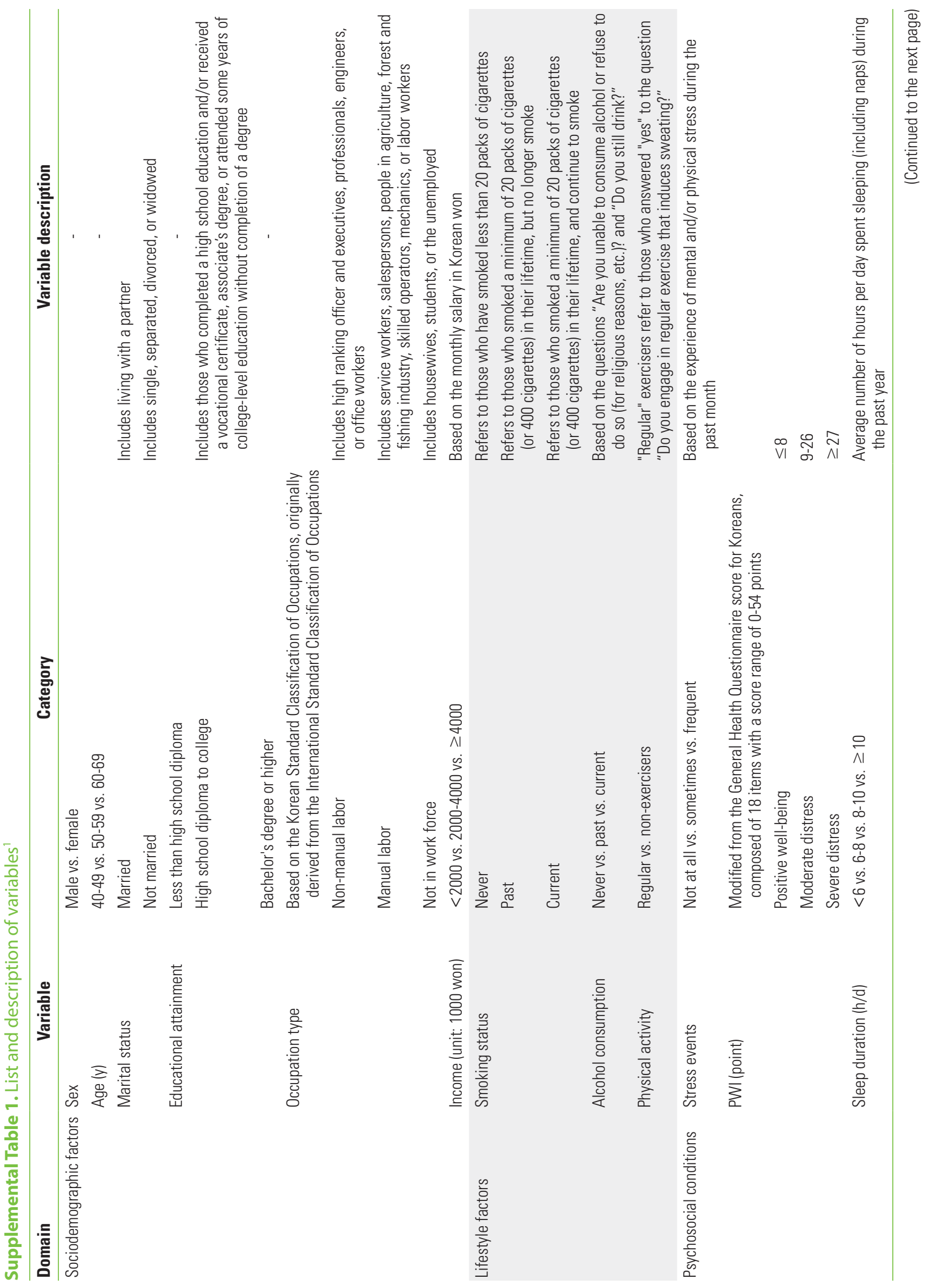




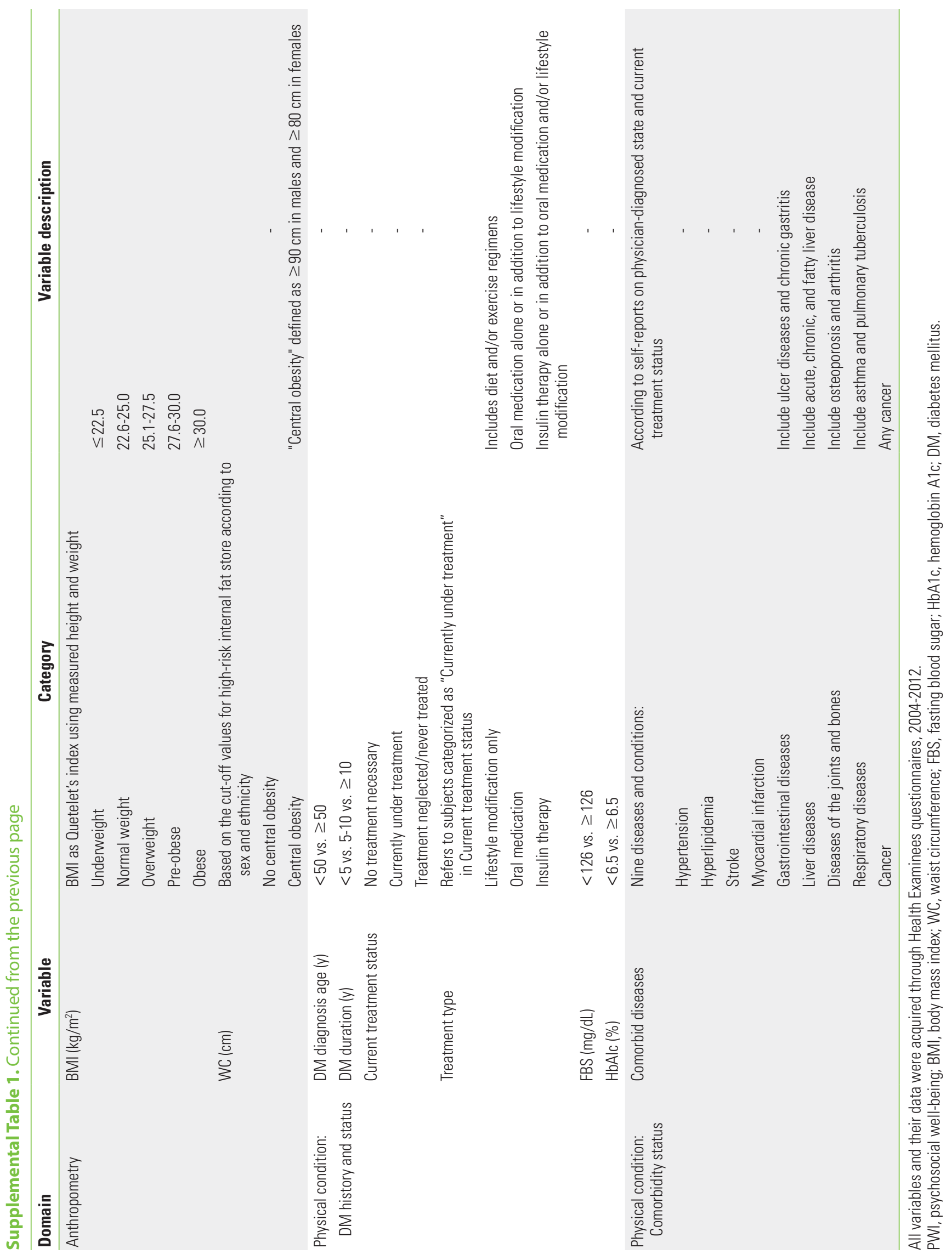

